\title{
Cross-amplification and characterization of microsatellite loci in Acropora austera from the south-western Indian Ocean
}

\author{
P.H. Montoya-Maya ${ }^{1,2}$, A.H.H. Macdonald ${ }^{2}$ and M.H. Schleyer ${ }^{1}$ \\ ${ }^{1}$ Oceanographic Research Institute, Durban, South Africa \\ ${ }^{2}$ School of Life Sciences, University of KwaZulu-Natal, Durban, South Africa \\ Corresponding author: P.H. Montoya-Maya \\ E-mail:phmontoya@gmail.com
}

Genet. Mol. Res. 13 (1): 1244-1250 (2014)

Received March 26, 2013

Accepted August 27, 2013

Published February 27, 2014

DOI http://dx.doi.org/10.4238/2014.February.27.9

\begin{abstract}
Here, we report the successful cross-species amplification of previously published acroporid microsatellite markers in the coral Acropora austera from the south-western Indian Ocean. This fastgrowing species is a major reef-building coral on South African reefs; however, it is the most damaged coral by scuba diving activity, and is known to be very susceptible to coral bleaching. Neither genetic information nor symbiont-free host tissue was available to develop novel microsatellite markers for this species. Cross-species amplification of previously published microsatellite markers was considered as an alternative to overcome these problems. Of the 21 microsatellite markers tested, 6 were reliably amplified, scored, and found to contain polymorphic loci (3-15 alleles). Although microsatellite sequences are believed to be scarce in the Acropora genome because of its small size, the results of this study and previous research indicate that the microsatellite sequences are well conserved across Acropora species. A detailed screening process identified and quantified the sources of error and bias in the application of these markers (e.g., allele scoring error, failure rates, frequency of null alleles), and may be accounted for in the
\end{abstract}


study of the contemporary gene flow of A. austera in the south-western Indian Ocean.

Key words: Acroporidae; Genetic markers; Genotyping; Marker transferability; Gene flow; South-east Africa

\section{INTRODUCTION}

Microsatellite loci are the genetic markers of choice in studies of gene flow or genetic connectivity, because they are co-dominant, highly polymorphic, species-specific, and offer adequate genetic resolution (Baums et al., 2006; Ridgway et al., 2008); however, microsatellite markers also have drawbacks. The isolation of novel microsatellite markers is expensive, time-consuming, and requires genetic information about the target species, which is often missing for non-model organisms (Selkoe and Toonen, 2006). For symbiotic cnidarians, such as acroporid corals, genetic information is obtained from symbiont-free host gametes (Baums et al., 2005; van Oppen et al., 2007; Nakajima et al., 2009), which is a technique that ensures molecular markers are cnidarian in origin. Mining for microsatellites in public sequence databases (Wang et al., 2009; Baums et al., 2009) and the cross-species amplification of previously published microsatellite markers (Nakajima et al., 2009) present alternative ways of overcoming the paucity of symbiont-free host tissue in cnidarians or of genetic information on non-model organisms.

Acropora austera is a reef-building, fast-growing coral, with a high population turnover, and is regarded as being opportunistic among reef corals (Macdonald et al., 2011). This branching coral is widespread across the Indian and Pacific Oceans. Although the species is found in a wide range of habitats on South African reefs, the colonies are more abundant in shallow areas (10-15 m) exposed to wave action (Celliers and Schleyer, 2001). It is the coral species most affected by scuba diving on South African reefs, and is very susceptible to coral bleaching (Schleyer MH and Montoya-Maya PH, personal observation). In addition, it is known to be preyed on by the crown-of-thorns starfish (Schleyer MH, unpublished data).

Macdonald et al. (2011) suggested that populations of A. austera along the south-east African coast exhibit a latitudinal gradient in genetic diversity (with it being higher in the northern reefs of the region), and that South African and Mozambican populations are connected. However, the same authors found a significant amount of fixation of allele frequencies among populations, which indicates a certain extent of demographic isolation (i.e., at ecological time scales) between A. austera populations in southern Mozambique and South Africa. To assess this apparent isolation at ecological time scales, the connectivity of this species is currently being assessed at various spatial scales using assignment methods and spatial autocorrelation analysis, which benefits substantially from the use of microsatellite markers (Manel et al., 2005; Selkoe and Toonen, 2006).

Microsatellite markers were missing for A. austera, while the de novo development of microsatellite markers was hindered by unsuccessful attempts to isolate symbiont-free host DNA (Montoya-Maya PH, unpublished data, 2011) and the paucity of genetic information on this species in public DNA databases. Cross-species amplification of previously published microsatellite markers was considered as an alternative to overcome these problems. Here, we successfully describe the cross-species amplification of 6 previously published acroporid mic- 
rosatellite markers in A. austera from reefs along the south-western Indian Ocean. This study focuses on the identification of transferable microsatellite markers, marker polymorphism evaluation, and quality control screening. The results of this study will facilitate individualbased genotyping of coral colonies in studies of contemporary genetic connectivity between reefs along the south Western Indian Ocean.

\section{METHODS}

\section{Selection of microsatellite markers for transferability tests}

We searched for previously published Acropora microsatellite loci in the literature, and selected 21 based on their high polymorphism and transferability across Acropora species, with preference being given to markers developed for Indo-Pacific species. Five markers (MS166, MS181, MS182, MS192, MS207) were selected that were originally developed for the Caribbean coral A. palmata (Baums et al., 2005), 7 markers (Amil2-02, Amil2-06, Amil207, Amil2-08, Amil2-10, Amil2-22, Amil2-23) for A. millepora from the Great Barrier Reef in Australia (van Oppen et al., 2007), and 9 markers (EST014, EST016, EST032, EST122, EST196, WGS051, WGS092, WGS101, WGS196) for the same species from the public expressed sequence tag (EST) and whole-genome shotgun (WGS) NCBI databases (http://www. ncbi.nlm.nih.gov/genbank/; Wang et al., 2009).

\section{Coral samples and DNA extraction}

A total of 287 tissue samples of $A$. austera from different reefs along the coasts of South Africa and Mozambique were collected by the Oceanographic Research Institute in South Africa, as part of a large coral genetic connectivity study. Sampled reefs included those within the iSimangaliso Wetland Park in South Africa, and the reefs at Inhaca Island and the Bazaruto Archipelago in Mozambique. Tissue samples were preserved in either 20\% dimethyl sulphoxide salt buffer ( 0.25 M EDTA; $20 \%$ (v/v) DMSO, saturated with $\mathrm{NaCl}$ ) or $96 \%$ alcohol $(\mathrm{EtOH})$ in the field, and subsequently stored at room temperature. In the laboratory, DNA was extracted from coral tissue using the ZR Genomic DNA Tissue extraction kit (Zymo Research, Irvine, USA) and following the manufacturer protocol.

\section{Marker transferability, specific amplification, and variability}

The 21 selected markers were initially amplified in 8 samples of $A$. austera. Around 50 ng of template was amplified in a $15 \mu 1$ polymerase chain reaction (PCR) containing $2.5 \mathrm{mM}$ $\mathrm{MgCl}, 0.5 \mu \mathrm{M}$ of each primer, $0.2 \mathrm{mM}$ dNTPs, $0.7 \mathrm{mg} / \mathrm{ml} \mathrm{BSA}$, and $0.7 \mathrm{U}$ Maxima HS Taq DNA polymerase (Fermentas). Pfu DNA polymerase (Fermentas) was added to the Maxima HS DNA polymerase in a 16:1 (unit to unit) ratio, to increase the fidelity and accuracy of PCR amplification (Matz M, personal communication, 2010). The following thermal cycle was used for the PCR: $95^{\circ} \mathrm{C}$ for $5 \mathrm{~min}, 35$ cycles at $95^{\circ} \mathrm{C}$ for $30 \mathrm{~s}$, annealing temperature of $-0.1^{\circ} \mathrm{C} /$ cycle, for $60 \mathrm{~s}, 72^{\circ} \mathrm{C}$ for $60 \mathrm{~s}, 72^{\circ} \mathrm{C}$ for $10 \mathrm{~min}$, and $10^{\circ} \mathrm{C}$ for $\infty$. The annealing temperature was $51{ }^{\circ} \mathrm{C}$ for all markers, except EST14, which was $61^{\circ} \mathrm{C}$. Gel electrophoresis analysis $(1 \%$ Agarose) indicated unsuccessful amplification in 6 loci (MS192, EST122, EST196, WGS092, 
WGS101, WGS196) and nonspecific amplification (i.e., more than 3 bands) in 4 loci (MS166, Amil2-08, EST032, WGS051); these loci were discarded from all subsequent analyses. The amplification of corresponding microsatellite sequences was confirmed by direct sequencing, in both directions, of 1 amplification product from each remaining locus using the Applied Biosystems BigDye Terminator v1.1 chemistry (Perkin-Elmer, Boston, MA, USA) on an ABI 3500 DNA Analyser (data not shown).

Eleven (Amil2-02, Amil2-06, Amil2-07, Amil2-10, Amil2-22, Amil2-23, MS181, MS182, MS207, EST14, EST16) successfully amplified microsatellite loci were tested on an additional 20 samples of $A$. austera. PCR products from the 1 st and 2 nd PCR screening were resolved on $8 \%$ polyacrylamide gels to determine size variation. Three loci (Amil2-02, Amil222, EST16) were invariant, and were excluded from all subsequent analyses.

\section{Genotyping of successfully amplified and variable loci}

Labeled primers were ordered for the remaining 8 loci, and used to amplify, in duplicate, the entire collection of 287 samples of $A$. austera. Four PCRs ( 2 multiplex and 2 standard) were carried out, as described in the previous section, except for primer concentrations, which varied, as shown in Table 1. Products were separated on an ABI 3500 DNA Analyser, and sized using the GeneScan LIZ 600 size standard (Applied Biosystems). Genotypes were compiled using STRand v2.4.59 (Toonen and Hughes, 2001). Scored peaks had a minimum intensity of $5 \%$ of the most intense peak, were in phase with the locus repeat motif, and, in the case of rare alleles, were present in 2 replicates. Two loci, MS207 and Amil2-06, were discarded, because they produced ambiguous peak patterns that made allele scoring difficult.

\begin{tabular}{|c|c|c|c|c|c|c|c|c|}
\hline Locus & Primer sequences $\left(5^{\prime}-3^{\prime}\right)$ & $\begin{array}{l}\text { Plex } \\
(\mu \mathrm{M})\end{array}$ & $\begin{array}{l}\text { Size range } \\
\quad \text { (bp) }\end{array}$ & $\mathrm{N}$ & $N_{\mathrm{A}}$ & $H_{\mathrm{O}} / H_{E}$ & $r$ & Species (source) \\
\hline Amil2-07 & $\begin{array}{l}\text { F: FAM-TAATGAGCAAACTCATTCATGG } \\
\text { R: CTTTTCCAAGAGAAGTCAAGAA }\end{array}$ & $\begin{array}{c}\text { I } \\
(0.4)\end{array}$ & $96-126$ & 283 & 3 & $0.028 / 0.035$ & 0.05 & $\begin{array}{l}\text { A. millepora } \\
\text { (van Oppen et al., 2007) }\end{array}$ \\
\hline Amil2-10 & $\begin{array}{l}\text { F: TET-CAGCGATTAATATTTTAGAACAGTTTT } \\
\text { R: CGTATAAACAAATTCCATGGTCTG }\end{array}$ & $\begin{array}{l}\text { II } \\
(0.2)\end{array}$ & $100-156$ & 287 & 5 & $0.014 / 0.045$ & 0.15 & \\
\hline Amil2-23 & $\begin{array}{l}\text { F: HEX-GCAAGTGTTACTGCATCAAA } \\
\text { R: TCATGATGCTTTACAGGTGA }\end{array}$ & $\begin{array}{c}\mathrm{I} \\
(0.1)\end{array}$ & $127-133$ & 287 & 4 & $0.035 / 0.135$ & 0.23 & \\
\hline MS181 & $\begin{array}{l}\text { F: FAM-TTCTCCACATGCAAACAAACA } \\
\text { R: GCCAGGATAGCGGATAATGA }\end{array}$ & $\begin{array}{l}\text { Single } \\
(0.5)\end{array}$ & $118-205$ & 246 & 15 & $0.642 / 0.734$ & 0.06 & $\begin{array}{l}\text { A. palmata } \\
\text { (Baums et al., 2005) }\end{array}$ \\
\hline MS182 & $\begin{array}{l}\text { F: FAM-TCCCACAACTCACACTCTGC } \\
\text { R: ACGCGGAAATAGTGATGCTC }\end{array}$ & $\begin{array}{c}\text { II } \\
(0.2)\end{array}$ & $132-228$ & 236 & 12 & $0.322 / 0.521$ & 0.21 & \\
\hline EST014 & $\begin{array}{l}\text { F: TET-CAGCTCCTTCATCTTCATCCT } \\
\text { R: AGCCGAAGAGGGGACAGAGT }\end{array}$ & $\begin{array}{l}\text { Single } \\
(0.5)\end{array}$ & $124-166$ & 282 & 13 & $0.663 / 0.650$ & 0.01 & $\begin{array}{l}\text { A. millepora } \\
\text { (Wang et al., 2008) }\end{array}$ \\
\hline
\end{tabular}

The primer concentration in single or multiplex PCR reaction (Plex), number of genotypes (N), number of alleles $\left(N_{\mathrm{A}}\right)$, observed $\left(H_{\mathrm{O}}\right)$ and expected $\left(H_{\mathrm{E}}\right)$ heterozygosity, and null allele frequency $(r)$ are presented. Significant $(\mathrm{P}<0.05)$ deviations from HWE and null allele frequencies are shown in bold.

\section{Quality control screening of microsatellite loci}

As quality control measures, we estimated the allele scoring error and average failure rates for each locus. Allele scoring error was assessed by comparing the duplicated genotypes, and was estimated from the number of incorrect genotypes divided by the number of repeated 
reactions (i.e., 287). Failure rates corresponded to the percentage of samples that could not be scored for 1 or more loci, either by unsuccessful amplification or unreliable scoring. MicroChecker v2.2.3 (van Oosterhout et al., 2004) was used to assess microsatellite genotyping errors caused by stuttering and large allele drop-out.

\section{Locus characteristics and Hardy-Weinberg equilibrium}

The estimated number of alleles, and observed and expected heterozygosities, were calculated using GenAlEx v6.4 (Peakall and Smouse, 2006). The frequency of null alleles for each locus was estimated by Micro-checker. Departures from Hardy-Weinberg Equilibrium (HWE) and evidence of linkage disequilibrium were tested in Arlequin v3.5.1 (Excoffier et al., 2005).

\section{RESULTS AND DISCUSSION}

The results demonstrated that 6 microsatellite markers (Table 1) previously developed for A. millepora and A. palmata, from both genomic DNA libraries and EST databases, could be applied to $A$. austera from the south-western Indian Ocean. This figure provides a $28 \%$ success rate ( 6 out of 21 primer pairs tested) in the cross-species amplification of acroporid microsatellite markers. The figure is comparable to the value of $33 \%$ obtained in a similar study in Japan (Nakajima et al., 2009), and is much higher compared to the success rate $(<11 \%)$ in developing novel microsatellite markers via genomic DNA library construction (van Oppen et al., 2007). Conversely, previous studies have found that many of the markers tested in this study, including those from the Atlantic A. palmata (e.g., MS181, MS182), successfully amplified reliable microsatellite loci in other Pacific Acropora species (Nakajima et al., 2009; Tang et al., 2010). In addition, previous studies have also reported nonspecific amplification in some markers (e.g., MS166, van Oppen et al., 2007), indicating that microsatellite sequences might be conserved; however, amplification steps require further optimization (Selkoe and Toonen, 2006). Although microsatellite sequences are believed to be scarce in the Acropora genome because of its small size (Márquez et al., 2002), the results of this study and previous research indicate that the microsatellite sequences that exist are well-conserved across Acropora species, particularly AAT microsatellites (Tang et al., 2010).

The allele scoring error of successful markers ranged from 0.1\% (Amil2-07) to $6.4 \%$ (MS181), and averaged 2.9\% across loci. This average scoring error rate is similar to the $2.7 \%$ obtained by Underwood et al. (2009) in a study of gene flow in A. tenuis using cross-amplified microsatellite markers. Although Micro-checker identified allele scoring errors because of stuttering for locus Amil2-23, the re-analysis of its DNA electropherograms showed no evidence of stuttering in this locus. The average failure rate was $5.9 \%$ across loci, and ranged from 0\% (Amil2-10 and Amil2-23) to 17.8\% (MS182). No evidence of scoring errors because of large allele drop-out was found in the dataset. It is recommended that the influence of these error rates should be assessed in estimates of gene flow, particularly for those based on individual multilocus genotypes (Selkoe and Toonen, 2006). Fortunately, there are software packages that offer bootstrapping techniques to accomplish this requirement.

Departures from HWE were observed in all loci $(\mathrm{P}<0.05)$, while linkage disequilibrium was observed between locus Amil2-23 and loci Amil2-10, MS181, and EST14 (P < 
0.05). The departures from HWE observed in these cross-amplified microsatellite markers are not sufficient reason to discard the loci (Selkoe and Toonen, 2006). The heterozygosity deficits that were detected in this study are in agreement with previous studies on corals and other marine organisms (see Underwood et al., 2009). In particular, similar results were observed for nuclear intron sequence data in the same species (Macdonald et al., 2011) and microsatellite loci in Pocillopora verrucosa (Ridgway et al., 2008) from the same reefs. Departures from HWE might be caused either by inbreeding, a Wahlund effect (i.e., mixing of differentiated gene pools leading to the compounding of genotypes from different reefs), or the presence of null alleles (Selkoe and Toonen, 2006). Although acroporid species are known to be characterized by strong inbreeding and clonality (Baums et al., 2006), which might account for some of the HWE deviations, they are most likely caused by a Wahlund effect and the presence of null alleles (Table 1). The presence of null alleles is expected when cross-amplifying microsatellite loci (Selkoe and Toonen, 2006; Chapuis and Estoup, 2007), and is a bias that may be accounted for in population genetic studies (Selkoe and Toonen, 2006; van Oosterhout et al., 2004). The rejection of linkage disequilibrium for Amil2-23 might be linked to the observed departures from HWE (see Excoffier and Slatkin, 1998).

\section{CONCLUSIONS}

Six carefully screened and selected genetic markers are now available for the study of genetic connectivity of $A$. austera, despite the unavailability of symbiont-free host tissue and genetic information in public DNA databases to develop novel host-specific primers. The microsatellite loci of Acropora species appear to be well-conserved, even across transoceanic species. An assessment of the value of these loci as genetic markers in phylogenetic studies of this genus is recommended. It is also encouraging that the sources of error and bias in the application of these markers could be quantified in contrast to similar studies (Selkoe and Toonen, 2006), and may be accounted for in the study of population structure of $A$. austera in the south-western Indian Ocean. Indeed, the population genetic structure of A. austera that is inferred from these microsatellite markers is discussed in another paper focusing on the genetic connectivity of this species in this region. Studies of this nature are invaluable in formulating a management strategy to ensure that south-east African coral reefs retain their biodiversity and resilience to climate change.

\section{ACKNOWLEDGMENTS}

We thank the South African Association for Marine Biological Research (SAAMBR) for financial support, and colleagues for $a d$ hoc assistance and help during the fieldwork. P.H. Montoya-Maya thanks Christiaan Labuschagne from Inqaba Biotechnical Industries (Pty) Ltd and Debora Sweby from SASRI for their instruction in applicable techniques. We are especially grateful for critical comments and suggestions from various anonymous reviewers. A South African National Research Foundation (NRF) PhD grant (to P.H. Montoya-Maya) supported this work, with additional support from the Western Indian Ocean Marine Association (WIOMSA) through a MASMA program grant (\#MASMA CC201006) to P.H. Montoya-Maya and M.H. Schleyer. 


\section{REFERENCES}

Baums IB, Hughes CR and Hellberg ME (2005). Mendelian microsatellite loci for the Caribbean coral Acropora palmata. Mar. Ecol. Prog. Ser. 288: 115-127.

Baums IB, Miller MW and Hellberg ME (2006). Geographic variation in clonal structure in a reef-building Caribbean coral, Acropora palmata. Ecol. Monogr. 76: 503-519.

Baums IB, Devlin-Durante MK, Brown L and Pinzon JH (2009). Nine novel, polymorphic microsatellite markers for the study of threatened Caribbean acroporid corals. Mol. Ecol. Resour. 9: 1155-1158.

Celliers L and Schleyer MH (2001). Acropora hyacinthus and Acropora austera dominance on a high-energy reef top at Kosi Bay. Coral Reefs, South Africa, 20-244.

Chapuis MP and Estoup A (2007). Microsatellite null alleles and estimation of population differentiation. Mol Biol. Evol. 24: 621-631.

Excoffier L and Slatkin M (1998). Incorporating genotypes of relatives into a test of linkage disequilibrium. Am. J. Hum. Genet. 62: 171-180.

Excoffier L, Laval G and Schneider S (2005). Arlequin (version 3.0): an integrated software package for population genetics data analysis. Evol. Bioinform. Online 1: 47-50.

Macdonald AHH, Schleyer MH and Lamb JM (2011). Acropora austera connectivity in the south-western Indian Ocean assessed using nuclear intron sequence data. Mar. Biol. 158: 613-621.

Manel S, Gaggiotti OE and Waples RS (2005). Assignment methods: matching biological questions with appropriate techniques. Trends Ecol. Evol. 20: 136-142.

Márquez LM, MacKenzie JB, Takabayashi M, Smith CR, et al. (2002). Difficulties in obtaining microsatellites from acroporid corals. Proc. 9th Int. Coral Reef. Symp. 1: 139-144.

Nakajima Y, Nishikawa A, Iguchi A and Sakai K (2009). Novel and cross-species amplifiable microsatellite markers in two Acropora species. Plank. Benth. Res. 4: 38-41.

Peakall R and Smouse PE (2006). GenAlEx 6: genetic analysis in Excel. Population genetic software for teaching and research. Mol. Ecol. Notes 6: 288-295.

Ridgway T, Riginos C, Davis J and Hoegh-Guldberg O (2008). Genetic connectivity patterns of Pocillopora verrucosa in southern African Marine Protected Areas. Mar. Ecol. Prog. Ser. 354: 161-168.

Selkoe KA and Toonen RJ (2006). Microsatellites for ecologists: a practical guide to using and evaluating microsatellite markers. Ecol. Lett. 9: 615-629.

Tang PC, Wei NV, Chen CW, Wallace CC, et al. (2010). Comparative study of genetic variability of AAT and CT/GT microsatellites in staghorn coral, Acropora (Scleractinia: Acroporidae). Zool. Stud. 49: 657-668.

Toonen RJ and Hughes S (2001). Increased throughput for fragment analysis on an ABI PRISM 377 automated sequencer using a membrane comb and STRand software. Biotechniques 31: 1320-1324.

Underwood JN, Smith LD, van Oppen MJ and Gilmour JP (2009). Ecologically relevant dispersal of corals on isolated reefs: implications for managing resilience. Ecol. Appl. 19: 18-29.

van Oosterhout C, Hutchinson WF, Wills DPM and Shipley P (2004). Micro-Checker: software for identifying and correcting genotyping errors in microsatellite data. Mol. Ecol. Notes 4: 535-538.

van Oppen MJH, Underwood JN, Muirhead A and Peplow L (2007). Ten microsatellite loci for the reef-building coral Acropora millepora (Cnidaria, Scleractinia) from the Great Barrier Reef, Australia. Mol. Ecol. Notes 7: 436-438.

Wang S, Zhang L and Matz M (2009). Microsatellite characterization and marker development from public EST and WGS databases in the reef-building coral Acropora millepora (Cnidaria, Anthozoa, Scleractinia). J. Hered. 100: 329-337. 